\begin{tabular}{|c|c|}
\hline & $\begin{array}{l}\text { International Journal of Trend in Scientific } \\
\text { Research and Development (IJTSRD) }\end{array}$ \\
\hline 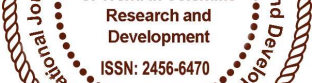 & International Open Access Journal \\
\hline 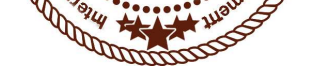 & ISSN No: 2456 - 6470 | www.ijtsrd.com | Volume - 2 | Issue - 2 \\
\hline
\end{tabular}

\title{
Land Information System (LIS) for Proper Residential Layout Management (Case Study of Tudun Wada Residential Layout, Potiskum, Yobe State, Nigeria)
}

\author{
Ibrahim Abubakar Audu \\ Geography Department, Yobe State University, \\ Damaturu, Yobe State, Nigeria
}

\author{
Hassan Audu Ahmed \\ Geography Department, Federal University Gashua, \\ Gashua, Yobe State, Nigeria
}

\section{ABSTRACT}

Land Information System (LIS) can provide us a better and more efficient system for land management. This was used to develop an efficient system for the management of Tudun wada residential layout plan in Potiskum Local Government Area of Yobe State, Nigeria. The study used Tudun wada residential layout plan obtained from Yobe state ministry of Land survey and town planning zonal office Potiskum. The layout plan was scanned and geo-referenced to UTM-32 projection in a GIS environment and using the four procedures of reality, conceptual design, logical design and physical design. Using Arc GIS 9.2, the study was able to achieve the efficient and effective management of the land of the study area with the ability to identify the layout parcels, it was designed for data generation to provide a database that will enhance data collection, storage, manipulation, retrieval and dissemination of information precisely at short time and eventually been able to query the database.

Keywords: LIS, database, layout, query

\section{INTRODUCTION}

Among the various natural resources that exist on this our planet (Earth), land is one of the basic natural resources that require a total preservation and management for the sustainable survival of the survivors on it. Land is the ultimate resource of the biosphere which refers to a specific area of the earth surface with physical entity in terms of its topography and spatial nature, and one of the characteristics of space that is widely recognized as a significant for planning and management purposes (Abbas et al., 2010). Land Information Management System (LIMS) is defined as the combination of human and technical resources, together with a set of organizing procedures that produce information on land in support of a broad range of managerial requirements (FIG, 1995). Data are raw collection of facts. Data relating to land may be acquired and held in alphanumeric form (for example books), or graphically (for example, as maps or aerial photographs), or digitally (for example, using electronic methods). To become information, the raw data must be processed so that it can be understood by a decision maker. Land information management system may be designed to serve one primary function or they may be multifunctional for supporting strategic planning. The focus is on determining organizational objectives and on the resources employed to achieve them. Some provide for management control and are concerned with the effective use of resources so as to accomplish an organization's objectives. Others are designed for operational control so that specific tasks can be carried out effectively and efficiently. Each requirement dictates a special set of information criteria and hence a special type of information system. Land information has been used in a variety of systems over the years; from register of deed, tract indexes to surveyors tie sheets or soil surveys. Today 
many organizations are moving land information into GIS.

Land information is an integral part of government, non-profit, and private sector activities. Adopting LIS technique can advance broader social purposes by making more effective public decisions and by using natural resources in a more optimal way. LIS supports spatial analysis and modeling procedure for solving complex planning and management problem. Information management system is an integrating technology where resources and activities are brought together to support the decision making process of an organization. By taking the advantage of Remote Sensing (RS) and Geographic Information System (GIS) technology, Land Record Information Management System for cadastral mapping was developed by integrating digital cadastral map and land record database. The fast development of society has been hastening the application of technologies especially LIS and technology in land administration. As an important facet of nature and society, land is attracting people's attention. The most attractive point which captures the interest of professionals and administrators is the changing policy of government about natural resources management and the application of technologies especially GIS in resources administration. The last decade has seen moves towards establishment of fully digitized land information systems throughout the world. It is recognized that cadastral systems are not ends in themselves. It is also recognized that digital cadastral systems must be tailored to facilitate an efficient land market as well as effective land-use administration and thereby, more generally, promote economic development, social cohesion and sustainable development (Enemark, 2007).

According to Dele and Mclaughlin (1998), land forms the basis for all forms of human activity, "from it we obtain the food we eat, the shelter we need, the space to work and the room we relax". The usefulness of land is enormous; therefore man has to guard it jealously considering its scarce nature. For this reason, conflicts most often arise in the sharing of resources or right of ownership of the land. This of course, is due to the rapid population growth of man on earth and his desires to explore land in myriad of ways. Partitioning of land therefore often generates anxiety among the beneficiaries; be it for administrative, economic hazards, environmental degradation and population growth for policy making in sharing of land parcel or resources thereon.

The resources of land are neither inexhaustible nor indestructible. The importance of land to human existence and the need to survey and manage effectively and efficiently for the use and good of mankind is very crucial. Therefore, for Nigeria's sustainable development, information relating to the location, size, use (residential, commercial, agricultural, industrial, educational, recreational, and cultural etc), contents/value, ownership and state of land must be aggregated as a system so that its administration would be less cumbersome and people driven. This means, land information is a pre-requisite for land administration (Molen, 2001). According to UN-ECE (2005) "Land information System (LIS) is defined as a tool for legal, administration and economic decision making and an aid for planning and development which consist on one hand a database containing spatially reference land related data for a defined area, and on the other hand procedures and techniques for the systematic collection, updating, processing and distribution of data. The base of a land information system is a uniform spatial referencing system for the data in the system which also facilitates the linking of data and within the system with other land related data". A land information system for state administration on land is expected to consist of the following components.
i. 4 Geospatial data
ii. Software and programs
iii. Hardware system (data server, workstation, computers, scanners, printers,
iv. Plotters, computer network: LAN, WAN, UPS etc)
v. The operators (surveyors, land officers etc)
vi. The integrated approaches and methods

Several advanced countries have pioneered system for using new technology in land information, which is receiving a wide acceptability in most developing countries like Nigeria. This acceptability in information technology on land is due to the fact that the uses of new information technology on land are receiving a wider awareness which the analogue system of land management are gradually been phased out. It is due to the fact that the new information technology has a variety of manipulation capacities, high accuracy, time saving and aids decision making. 
This study is limited to Tudun wada residential layout plan of Potiskum Local Government Area of Yobe State, Nigeria and it lies within latitude $11^{\circ} 42^{\prime}$ to $11^{\circ} 41^{\prime}$ and longitude $11^{\circ} 05^{\prime}$ to $11^{\circ} 04^{\prime}$.

\section{Materials and Method}

The layout coordinates reading were carried out using the GPS while other details about the land parcels and owners were obtained from the Yobe state ministry of lands, survey and town planning. The Tudun wada residential layout plan of Potiskum Local Government Area of Yobe State that was used for this study was acquired from Yobe state ministry of land survey and town planning Zonal office Potiskum. The Tudun wada residential layout plan was scanned and georeferenced using the coordinate obtained from the field. The coordinates obtained were UTM coordinates and the plan geo-referenced in the UTM zone 32. The database was created using the four levels of reality, conceptual design, logical design and physical design.

\section{a) Reality Articulation}

Reality Articulation refers to the phenomena as it actually exist, including all aspect that may or may not be perceived by individuals.

\section{b) Conceptual Design}

This is the human conceptualization of reality and how each object is to be represented so as to satisfy the information requirement. Three types of representation exist and these are tessellation, vector and object oriented. The vector base conceptual design was used for this study due to the ability of this approach to capture and store X, Y coordinates as shown in table 1 .

Table 1: Entities and attributes

\begin{tabular}{|l|l|}
\hline Entitles & \multicolumn{1}{|c|}{ Attribute } \\
\hline Road & ID, class, name \\
\hline Parcel & ID, owner, use, Beacon \\
\hline
\end{tabular}

\section{c) Logical Design}

The logical aspect of the database design is the representation of the data model designed to reflect the recording of the data in computer system, it is often referred to as data structures that translate the conceptual data model using a relational data structure Ojigi et al, (2011). d) Physical Design

The physical design is the representation of the data structure in the format of the implementation software and this was done at the beginning of the database creation as seen in figures 1 and 2 .

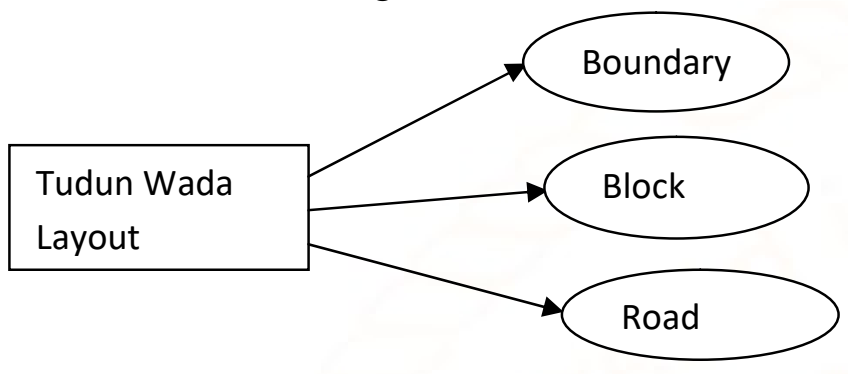

Figure 1: Design model of the study area showing boundary block of parcel, road relationship. Source: Author, 2011

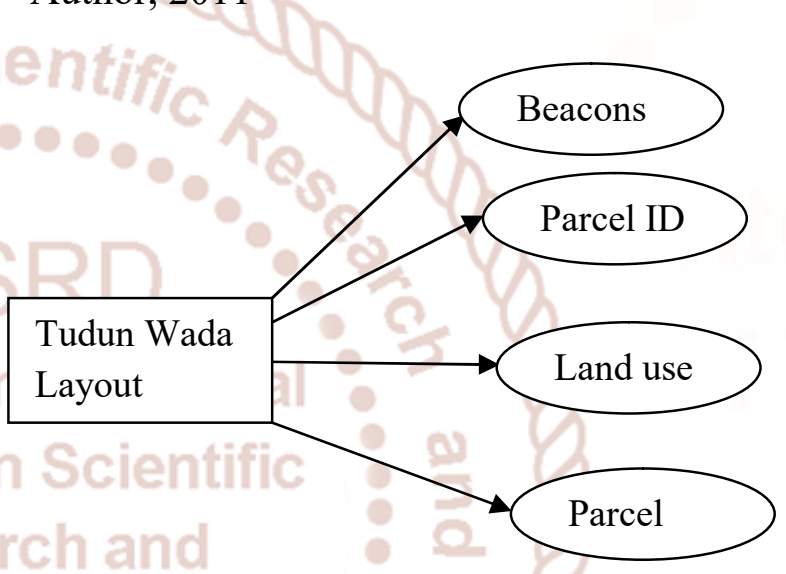

Figure 2: Design model of study area showing parcel, parcel owner, beacon and land use. Source: Author 2011

\section{e) Database Creation}

The database was created by inputting the spatial data and attribute data into the computer system. The attribute data were inputted and stored in a tabular form. The spatial data were acquired by scanning the hard copy map using A3 scanner with photo-plus, geo-referenced and digitized on-screen in Arc map environment under the following layers: point, line and polygons. The graphics were linked with the created spatial database after editing and GIS operation and analysis carried out.

\section{Results and Discussion}

According to Uluocha (2007), “Querying or searching a database is a common function of LIS. This involves probing the database to see if certain specified relationships or conditions exist among some features or data items". Spatial query was carried out to get information about parcels. Different information can be accessed or realized depending on 
what the user wants. These can be realized with the even do more by showing the attribute data of the of help of queries as carried out and shown in figure 4. Roads were extracted separately, parcels with layout plan for easy identification of parcel owner, certificate of ownership were sorted out, development area were sorted out, land use of the study area was classified and all the result shown. It is possible to

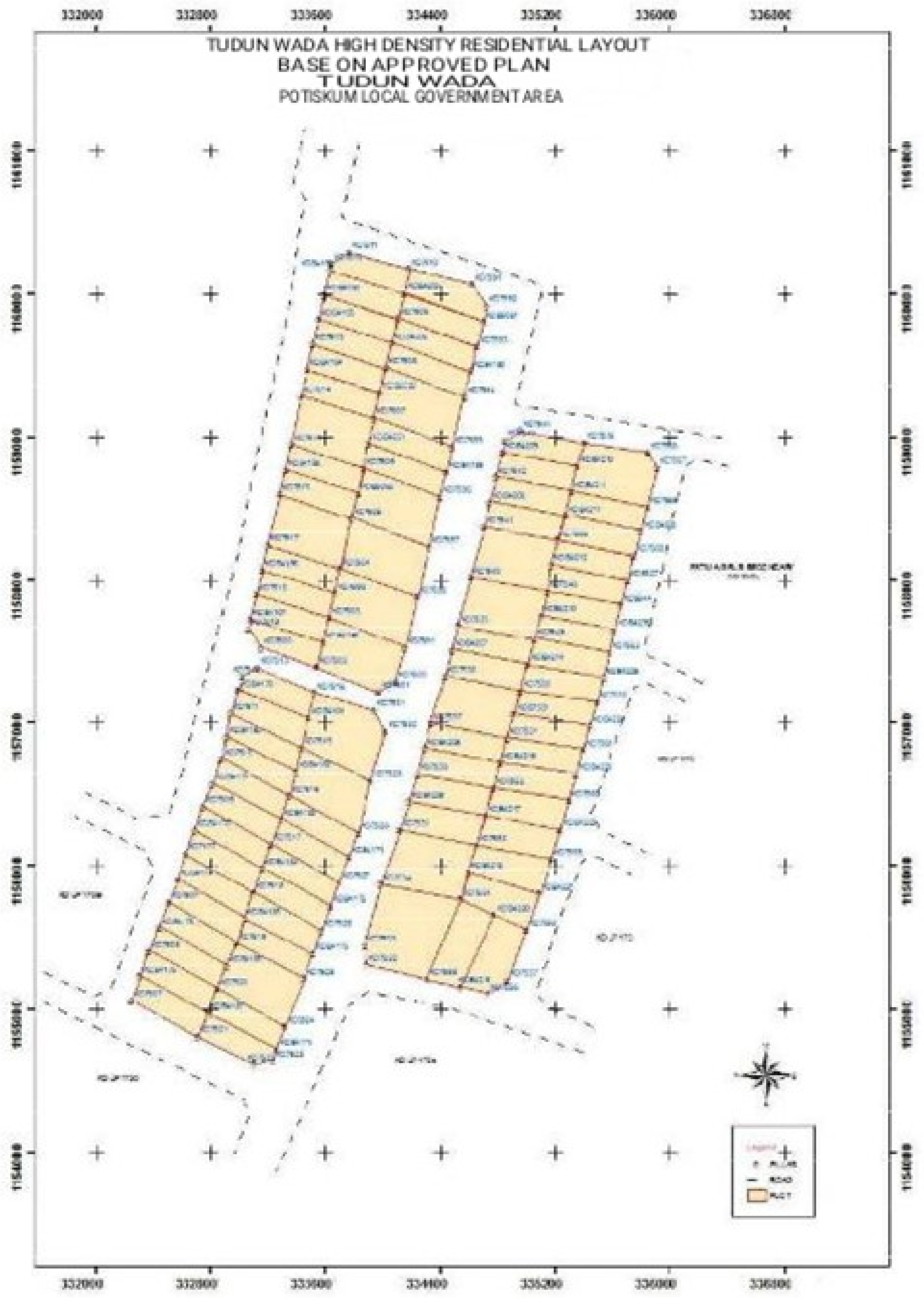

Figure 3: Individual plots of land in the Tudun wada residential layout plan. 
International Journal of Trend in Scientific Research and Development (IJTSRD) ISSN: 2456-6470

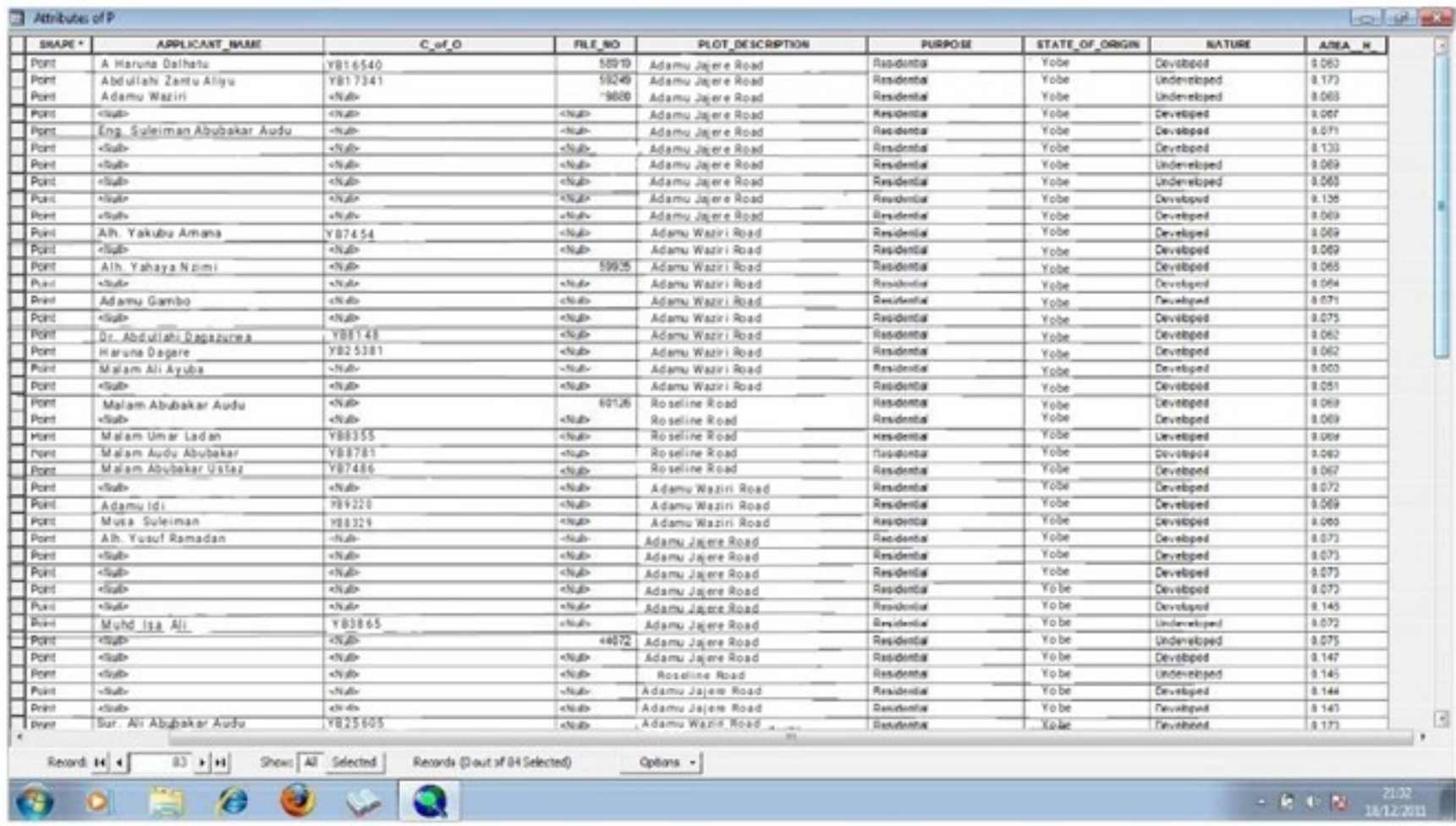

Figure 4: Database of the layout

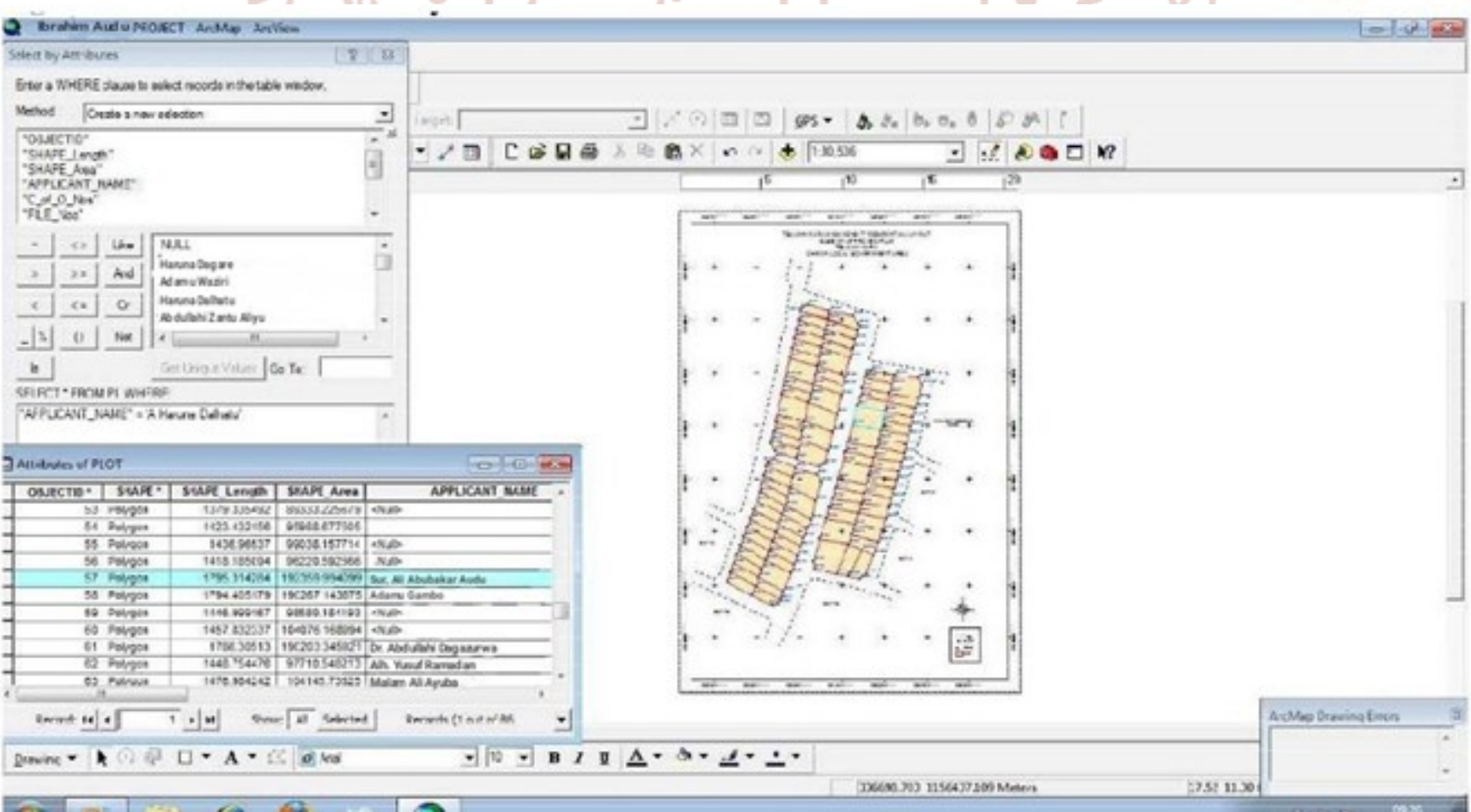

Figure 5: Typical query showing the plot of Sur. Ali Abubakar Audu 
International Journal of Trend in Scientific Research and Development (IJTSRD) ISSN: 2456-6470

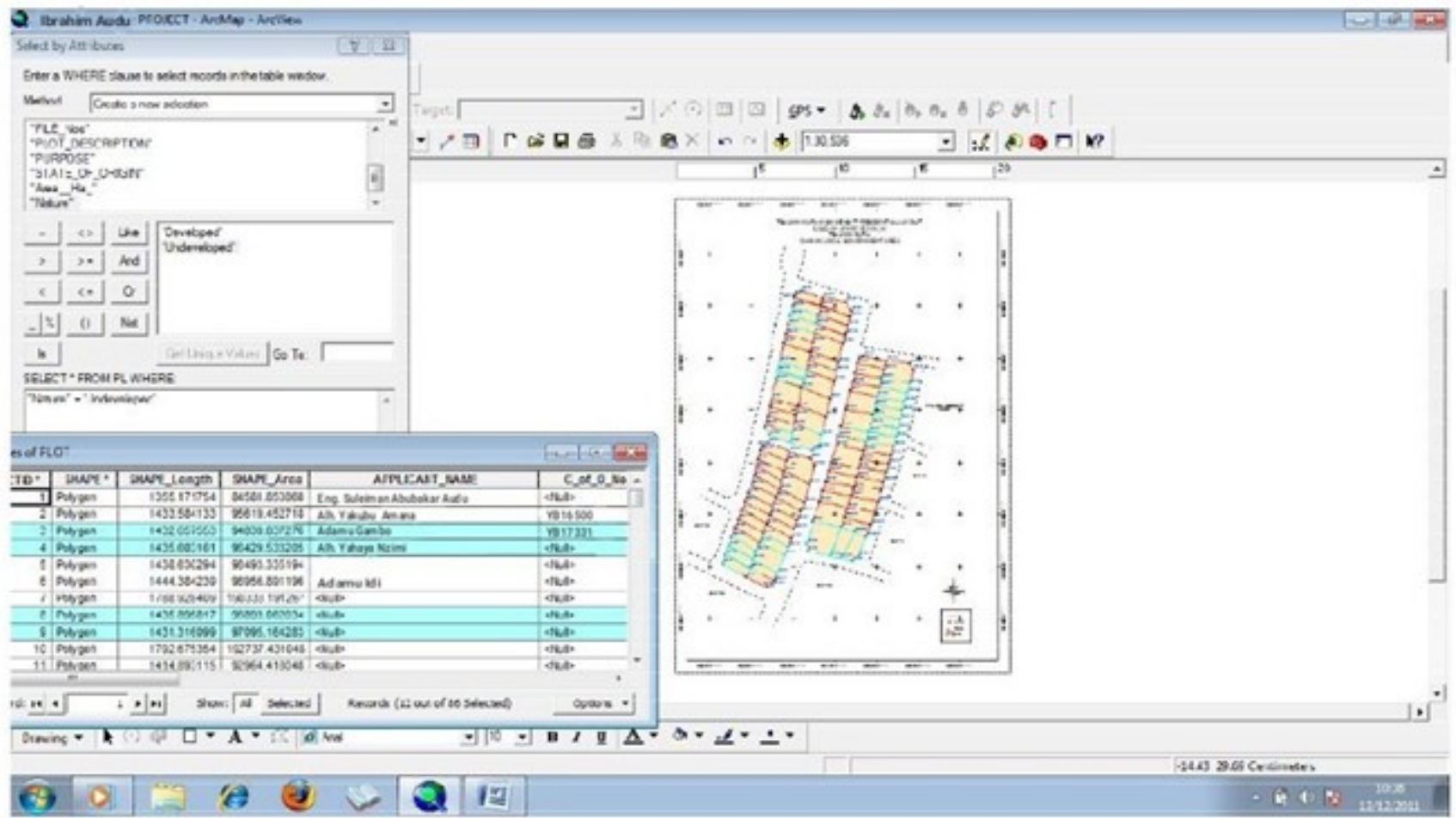

Figure 6: Query showing the undeveloped plots

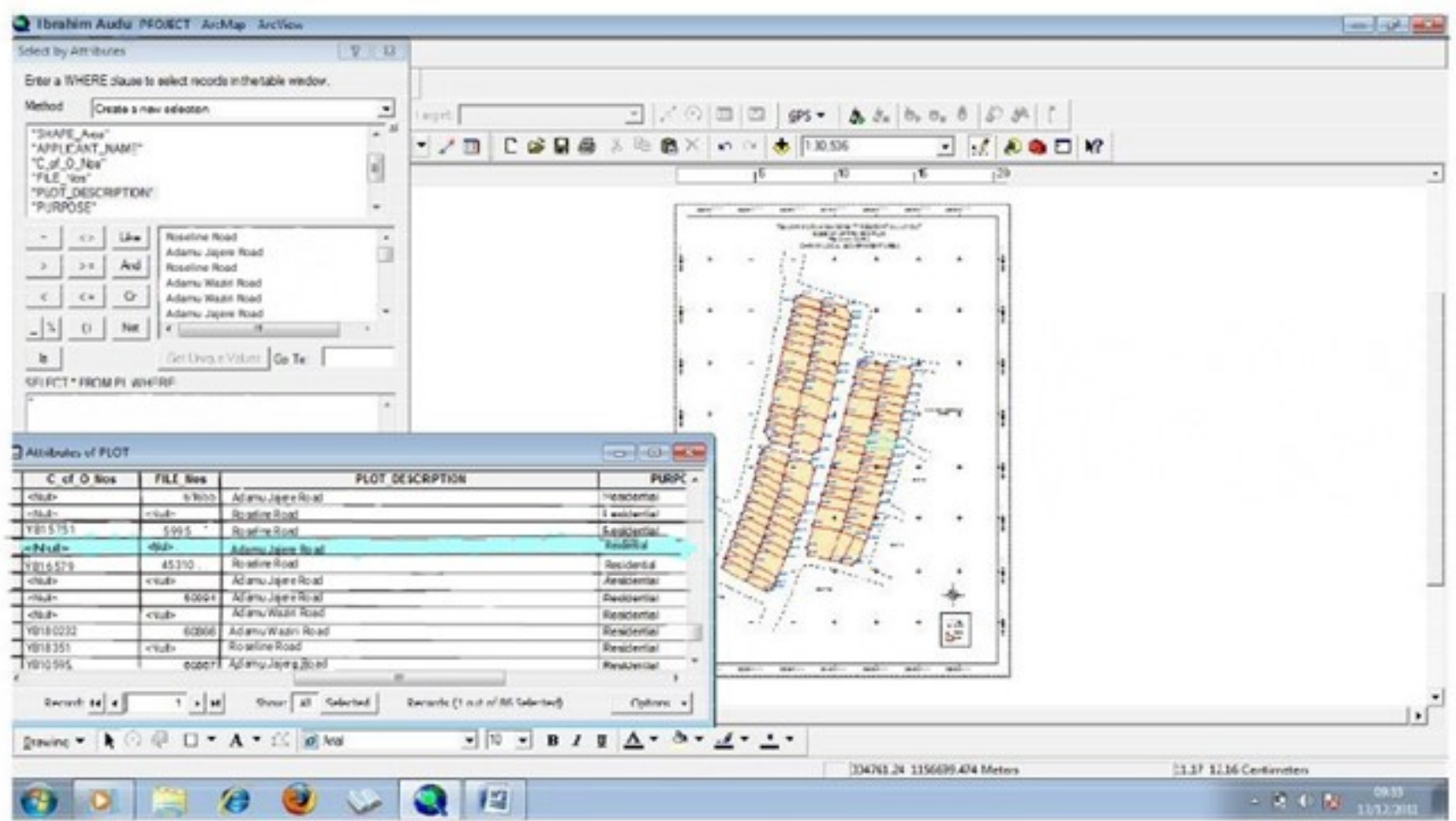

Figure 7: Query showing plots located at Adamu Jajere road 


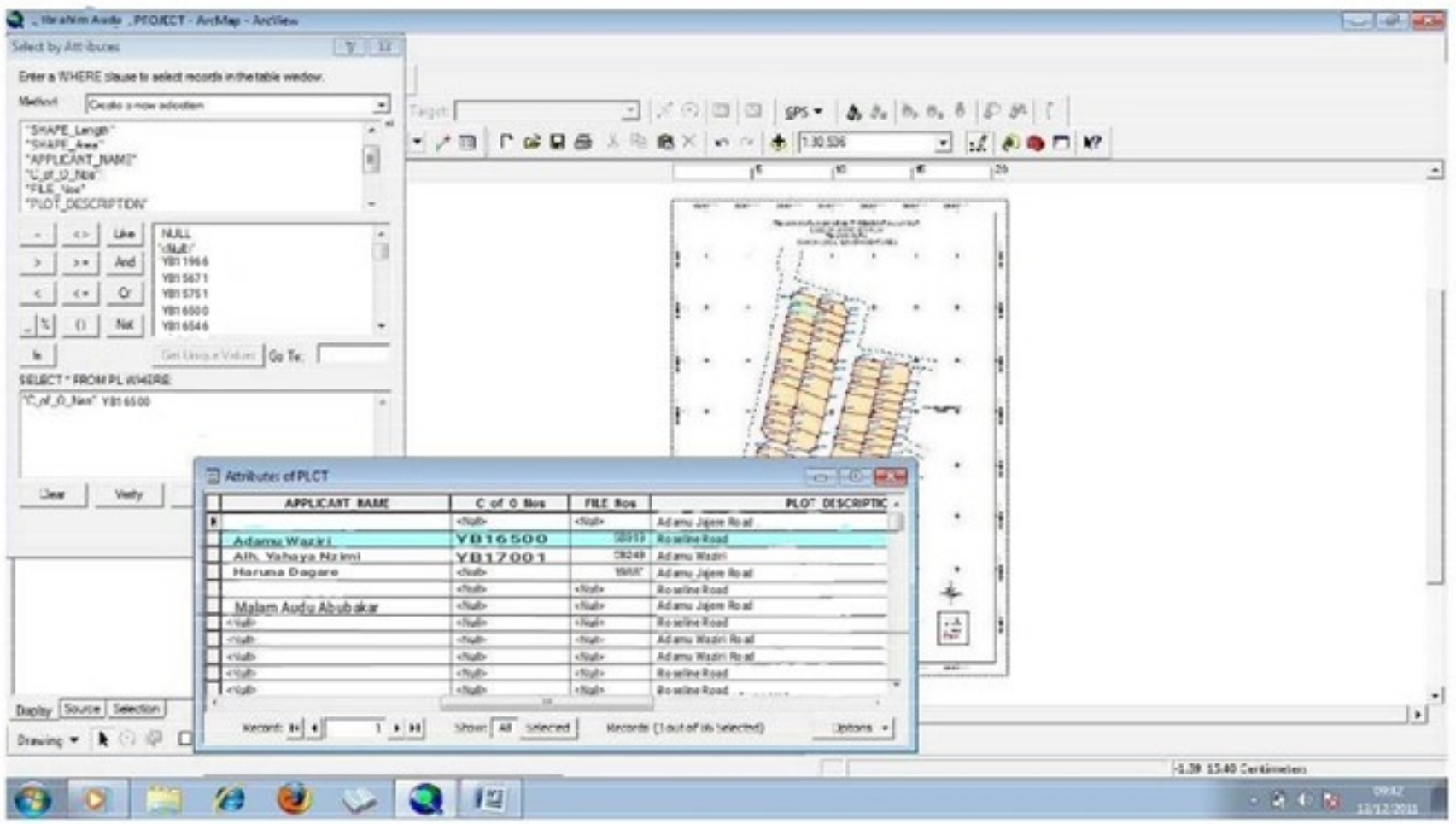

Figure 8: Query showing plot with C of O number YB16500

This study was carried out employing Geographic Information System (GIS) in developing a Land Information System (LIS) for the management of Tudun wada residential layout in Potiskum Local Government area of Yobe state, Nigeria. In order to achieve this, the study captured geographic data (coordinates) using Global Positioning System (GPS) receiver so as to provide geographic location for the layout plan. The study also provided a database of Tudun wada residential area and linked the database to the layout plan. The study was able to generate the plan of the layout and the exact location of the plots located at Tudun wada residential layout (figure 3); which was also created a database for the area (figure 4). Running of a spatial analysis on the plots of land to query plots owners and status of development is possible (figures 5, 6, 7 and 8).

\section{Conclusion}

Land Information System (LIS) can provide us a better and more efficient system for land management. LIS is a digital system having spatial (graphical) and attribute data for each land holding since the two are maintained in a digital form, it is possible to edit, maintain, rectify and keep the record up to data with least efforts. It can give reprieve to both land owners as well as the Government, which requires information for planning and implementation whereas people have access to information regarding their own holdings; the government will be able to extract information for the entire area of interest. It will also be able to maintain and track changes, detect errors, make online correction, and make land management a process dependent activity rather than people dependent.

Advancement in the information communication technology has lessened the burden of carrying about large paper in the name of maps or plans; one must also not trouble himself with searching through old and dusty cupboards for worn out or form hard copies of maps or plans which may only take the grace of God to find at the end of the day. From the database, other derived maps are possible due to the existence of the spatial database it is possible to get result of both spatial and non spatial question with ease from the database.

Currently in Nigeria, cadastral surveys are tied to different origins and the scale at which the plans are charted may vary from state to state. In order to have data compatibility, for a seamless database of our cadastral maps, there is need for national coordination in order to harmonies the origin, scale and accuracy of our plans. There is need for awareness to be created at 
all level of government towards deriving the benefits of GIS technology in Yobe state and Nigeria as a whole. There is also the need for amendment of existing survey laws to accommodate the existence of new technologies. A beginning has to be made and the first step in this direction is to provide the basic infrastructure. This can be done by making cadastral maps digital and also by taking the exercise of converting all record of rights in one language and again making the database available. Success is a journey not a destination therefore one man's success may be another's beginning of the journey. There is need for projects like this to be carried out and improvements should be made upon.

\section{References}

1) Abbas, I.I; Muazu, K.M and Ukoje, J.A (2010). Mapping Land use- land cover and Change Detection in Kafur Local Government, Katsina, Nigeria (1995-2008) Using Remote Sensing and GIS. Research Journal of Environmental and Earth Sciences, 2010 Vol.2.Issue 1, pp 6- 12.

2) Dele P.F and Maclaughlin, (1998).n Land Information Management: An introduction with spatial reference to cadastre problems in third world countries. Clear Dem Press Oxford.
3) Enemark, S., Williamson, I., and Wallace, J. (2005). Building Modern Land Administration Systems in Developed Economies. Journal of Spatial Science, Perth, Australia, Vol. 50, No. 2, pp 51-68.

4) FIG (1995): Statement on the Cadastre. FIG publications number 11. FIG Office, Copenhagen. Retrieve August 22, 2017 from http://www.fig7.org.uk/publications/cadastre/state $\mathrm{m}$ ent_on_cadastre.html

5) Molen, Paul van der (2001). The Importance of the Institutional Context for Sound Cadastral Information Management for Sustainable Land Policy; Proceedings of FIG International Conference on Spatial information for Sustainable Development, Nairobi, Kenya, 2-5 October 2005. Retrieve August 25, 2017 from http://www.fig.net /pub/proceedings/nairobi/vandermolen-TS7-4.pdf

6) Uluocha, N. O. (2007). Maps and Sustainable Economic Development. Nigerian Journal of Business and Social Sciences, New Series, Vol.1. No.

7) UN-ECE (2005). Land Administration in the UNECE Region - Development trends and main principles. UNECE, Geneva. Retrieve August 25, 2017 from http://www.unece.org/env/docum ents/2005/wpla/ECE-HBP-140-e.pdf 